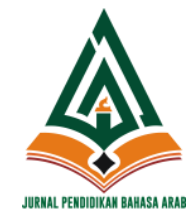

\author{
Alibbaa': Jurnal Pendidikan Bahasa Arab \\ Vol. 2 No. 2, Juli 2021 \\ P-ISSN: 2721-1606 | E-ISSN: 2716-4985 \\ doi: https://doi.org/10.19105/alb.v2i2.4798
}

\title{
Cooperative Learning Dalam Bahasa Arab: Metode Belajar di MA Nurul Huda
}

\section{Satriadi, Muassomah}

State Islamic University of Maulana Malik Ibrabim Malang, Indonesia E-mail: somabwibisono@gmail.com

\section{Abstract}

The paper elaborates about the application of Arabic learning with the Cooperative Learning method, along with the results obtained after applying this method to 11 students of class XI MA Nurul Huda Pandan Jaya. This research used a qualitative descriptive approach with observation, interview and documentation research instruments. The results showed that the applied Cooperative Learning method is able to affect student's outcomes, besides that students are more motivated to think more critically in solving problems in the form of discussions, and are more courageous to express their arguments both in their groups and to deliver to the class.

Keywords: Cooperative Learning, Arabic language, Application. 


\section{Pendahuluan}

Cooperative Learning merupakan metode pembelajaran yang efektif dalam proses belajar, termasuk pembelajaran bahasa Arab ${ }^{1}$. Siswa dapat melakukan kerja sama dengan siswa lain secara berkelompok dalam menjalani proses belajar. Bahasa yang memiliki karakter sebagai alat komunikasi dan interaksi dengan sesame telah membutuhkan kerja kolektif dan partnership. Kerja kolektif dapat saling memberikan support dan semangat dalam mengaplikasikan bahasa Arab dari berbagai keterampilan. Siswa secara berkelompok dapat saling membantu, menjelaskan, dan mengaplikasikan keterampilan berbahasa secara bergantian. Selain itu mereka dapat saling memberikan penjelasa, dan mengajukan tanya jawab hingga terbentuknya cara belajar yang kreatif dan inovatif. Dengan kata lain, metode Cooperative Learning membuat siswa memiliki peningkatan kompetensi berbahasa Arab.

Studi-studi terkait Cooperative Learning dalam pembelajaran telah memiliki tiga kecenderungan. Petama, Cooperative Learning merupakan sebuah strategi pembelajaran dalam pembelajaran matematika ${ }^{2}$. Di mana hasil belajar matematika bagi siswa telah mengalami peningkatan ${ }^{3}$. Kedua, strategi kooperatif learning juga diterapkan dalam pembelajaran olah $\mathrm{raga}^{4}$. Cooperative Learning dengan menggunakan STAD mendorong siswa memiliki kemampuan motoric tinggi dan memberikan pengaruh yang lebih bai, seperti pengalaman gerak, lingkungan, dan fasilitas yang memadai hingga hasil belajar meningkat. Ketiga, kooperatif learning sangat efektif

\footnotetext{
${ }^{1}$ Wahyuni, A., \& Abadi, A. M., "Perbandingan Keefektifan Pembelajaran Cooperative Learning Type STAD dan Type TPS Pada Pembelajaran Bangun Ruang Siswa SMP”. Jurnal Riset Pendidikan Matematika, Vol. 1 No. 2, 2014: 164.

${ }^{2}$ Alwan, M., "Pengaruh Strategi Pembelajaran Cooperative Learning Tipe Rotating Trio Exchange Terhadap Prestasi Belajar Matematika Siswa Mts", Jurnal AlMuta'aliyah STAI Darul Kamal NW Kembang Kerang, 2020.

${ }^{3}$ Erita, S., "Beberapa model, pendekatan, strategi, dan metode dalam pembelajaran matematika", Tarbawi: Jurnal Ilmu Pendidikan, Vol. 1 No. 2, 2016:35.

${ }^{4}$ Setiawan, A., Yudiana, Y., Ugelta, S., Oktriani, S., Budi, D. R., \& Listiandi, A. D. (2020). Hasil Belajar Pendidikan Jasmani dan Olahraga Siswa Sekolah Dasar: Pengaruh Keterampilan Motorik (Tinggi) dan Model Pembelajaran (Kooperatif). TEGAR: Journal of Teaching Physical Education in Elementary School, Vol. 3 No. 2, 2020: 68 .
} 
dilakukan dalam membetuk karakter peserta didik ${ }^{5}$. Setiap siswa mendapatkan kesempatan untuk menjadi pemimpin dalam setiap tim, siswa mendapatkan pengalaman sikap kepemimpinan, selain itu memberikan peluang kepada untuk belajar dan dan berinteraksi dengan latarbelakng yang berbeda-beda ${ }^{6}$. Dengan kata lain, Cooperative Learning yang merupakan salah satu metode yang cocok digunakan dalam metode pembelajaran saat ini dengan mengedepankan prinsip kerjasama antar kelompok sehingga siswa mampu memperoleh pengalaman belajar yang lebih optimal dan intens. ${ }^{7}$

Tulisan ini bertujuan untuk melengkapi penelitian yang ada tentang Cooperative Learning sebagai strategi dan metode belajar. Sejalan dengan itu, tulisan ini merumuskan pertanyaan: bagaimana bentuk dari perubahan siswa dalam proses dan hasil belajarnya berupa peningkatan mutu serta kualitas belajar setelah diterapkannya metode Cooperative Learning. Metode ini perlu dilakukan agar proses belajar lebih efektik dan memberikan kesempatan lebih luas pada siswa dalam menggali dan menerapkan materi yang sudah dipelajari.

Tulisan ini berlandaskan sebuah argument bahwa Cooperative Learning yang digunakan dalam proses belajar mengajar bahasa Arab, telah meningkatkan kompetensi berbahasa Arab siswa. Siswa berperan aktif dalam kegiatan belajarnya, berinteraki dengan antar siswa, yang hhal ini dapat membangun semangat belajar dan lingkungan berbahasa siswa. Dengan demikian, metode Cooperative Learning yang telah diaplikasikan membuat siswa lebih aktif dan antusias mengikuti tahap demi tahap pembelajaran bahasa Arab.

\footnotetext{
${ }^{5}$ Dalimunthe, M., \& Suyanti, R. D. Pembentukan karakter dan peningkatan hasil belajar kimia siswa sma melalui pengintegrasian strategi dan media pembelajaran pada materi hidrokarbon. -, 5(02), 2016.

${ }^{6}$ Zaman, B, "Implementation of Cooperative Learning Strategies in Islamic Religious Education". IJECA (International Journal of Education and Curriculum Application), Vol. 3 No. 2, 2020: 91-97.

${ }^{7}$ Nurhadi, Pembelajaran Kontextual (Contextual Teaching dan Learning/CTL) dan Penerapannya dalam KBK, (Malang: UIN Press, 2004), 60.
} 


\section{Metode Penelitian}

Penelitian ini dilakukan dengan menggunakan metode deskriptif kualitatif yang berlandaskan pada fenomena tentang penggunaan metode Cooperative Learning dalam pembelajaran bahasa Arab. Tema ini dipilih atas dasar bahwa pembelajaran bahasa Arab di sekolah MA Nurul Huda, khususnya di kelas XI, sejauh ini masih belum bisa menciptakan siswa aktif dalam menggunakan bahasa Arab, hingga diperlukan metode belajar yang dapat mengubah situasi tersebut. kondisi tersebut dapat dipecahkan dengan Cooperative Learning dalam proses belajar siswa.

Data dalam penelitian ini dikumpulkan dengan menggunakan dua cara, yaitu observasi dan wawancara. Observasi dilakukan dengan melakukan pengamatan di dalam kelas bahasa Arab, dengan memperhatikan dan mengamati setiap aktivitas yang dilakukan siswa selama proses belajar bahasa Arab dengan menggunakan metode Cooperative Learning. Wawancara dengan siswa dilakukan secara offline, karena pada saat dilakukan penelitian daerah ini berstatus hijau dari wabah Covid-19, hingga sistem pendidikan di MA Nurul Huda dilakukan secara offline dengan tatap muka di sekolah dan di kelas seperti biasanya. Wawancara berlangsung pada jam istirahat setelah pelajaran di laksanakan, dan sebagian dilanjutkan pada saat jam pulang sekolah. Bahan wawancara tentang pengalaman siswa menjalani belajar dengaan metode kooperatif learning.

Setelah data dari hasil obeservasi dan wawancara terkumpul, selanjutkan dilakukan analisis data dengan menggunakan tiga tahapan, yaitu reduksi data, display data dan penarikan kesimpulan ${ }^{8}$. Reduksi data dilakukan dengan cara memilih dan memilah data yang sesuai dengan tema yang ditentukan dengan membuang beberapa data yang tidak terkait dengan penelitian. Display data dilakukan dengan cara memamaparkan data yang diperoleh di lapangan. Dalam penelitian ini data didisplay dengan menyajikan foto pada saat proses belajar sedang berlangsung, selain itu data hasil wawancara didispaly dalam tabel yang selajutkan didiskripsikan dengan menentukan kategorisasikategorisasi. Tahap selajutnya penarikan kesimpulan, setelah melakukan perenungan dan analisis terhadap data yang terkumpul.

\footnotetext{
${ }^{8}$ Moleong, L. J., \& Edisi, P. R. R. B., Metodologi Penelitian. Bandung: Penerbit Remaja Rosdakarya.
} 


\section{Hasil dan Pembahasan}

\section{Penyusunan dan Penerapan Pembelajaran Cooperative Learning}

Untuk lebih memudahkan dalam memahami data yang telah didapatkan dilapangan maka dalam paragraf ini dibahas hasil serta pembahasan data yang didapat setelah melaksanakan proses pengambilan data yang dibutuhkan di kelas XI pada MA Nurul Huda Pandan Jaya, mengenai pembelajaran Cooperative Learning dalam meningkatkan hasil belajar para siswa. Hal ini dapat dilakukan melalui beberapa tahapan. Pertama, Praktek Mengajar dengan metode Cooperative Learning. Hasil observasi pertama dengan melakukan praktek mengajar dengan metode Cooperative Learning. Pada bagian ini peneliti secara langsung melaksanakan praktek mengajar pada kelas XI MA Nurul Huda Pandan Jaya dengan jumlah siswa 11 orang, adapun kegiatan yang dilakukan yaitu:

Kegiatan pertama, sehari sebelum kegiatan ini dilakukan, peneliti melakukan survei ke sekolah untuk memastikan proses kegiatan belajar yang dilakukan disekolah MA Nurul Huda, dan juga bersosialisasi dengan para guru serta kepala sekolah untuk meminta izin diadakannya penelitian ini, sekaligus meminta izin untuk kegiatan ini.

Kegiatan kedua, dihari berikutnya, kegiatan dimulai dengan peneliti masuk kedalam kelas dan memberi salam kemudian mengecek kehadiran siswa, kemudian memberikan beberapa kalimat pengantar awal agar terdapat rasa semangat dan motivasi untuk mengikuti kegitan pembelajaran.

Kegiatan ketiga, setelah kelas dirasa cukup kondusif dengan tertibnya para siswa, peneliti memberikan materi yang akan menjadi sasaran dalam mengembangkan metode Cooperative Learning, adapun materi yang digunakan ialah pengenalan mufrodat berupa beberapa keterang tempat (ظروف المكان) dimana materi berupa beberapa mufrodat di tulis dipapan tulis, kemudian dibaca, dipahami, dan dihapalkan secara bersama-sama.Kemudian setelah memaparkan materi dan memulai sedikit diskusi kecil dengan menanyakan tingkat kepahaman para siswa, membagi para siswa kedalam beberapa kelompok, untuk pembagian ini, memberika pilihan kepada dalam siswa membagi kelompoknya dengan mempertimbangkan beberapa aspek, utamanya ialah aspek kecakapan akademik dalam 
belajar.Setelah didapatkan kelompok, peneliti memberikan tugas berupa menguji tingkat kepahaman mereka yaitu, menghapal mufradat yang telah disamapikan, kemudian meminta untuk mereka menuliskan kembali mufradat tersebut dengan sebelumnya menghapus mufradat yang telah ditulis dipapan tulis.

Pada tahapan akhir meminta setiap kelompok mengumpulkan tugas yang telah diberikan, setelah itu meminta perwakilan dari tiap kelompok untuk maju kedepan kelas dan menuliskan mufrodat dipapan tulis secara bersamaan dan menilai secara bersama hasil kerja dari perwakilan tiap kelompok.

Berikut ini merupakan beberapa foto saat praktek mengajar dengan metode Cooperative Learning:

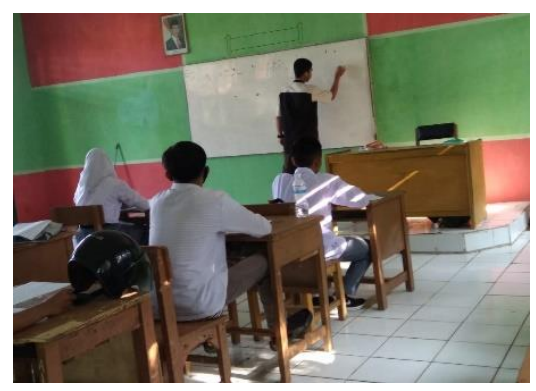

Penulisan Materi Diskusi

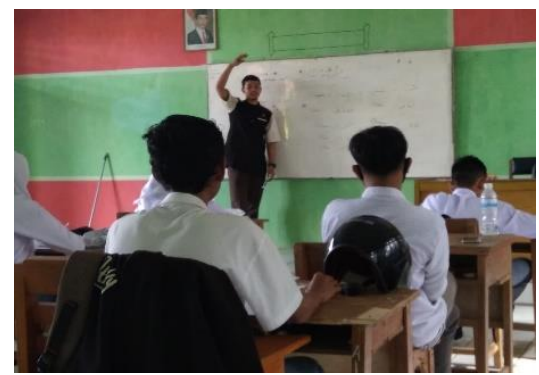

Melafalkan dan Menghafal Bersama

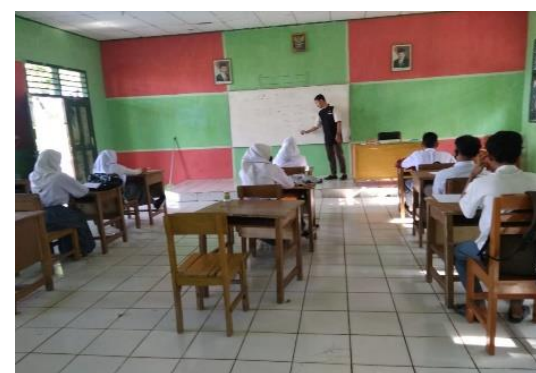

Penjelasan Materi Diskusi

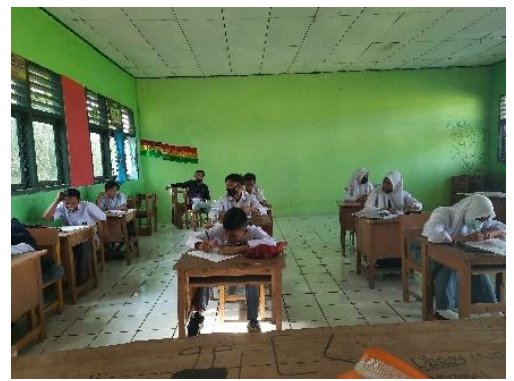

Kelompok Putra Putri

Setelah dilaksanakan pembelajaran berbasis Cooperative Learning tersebut didapati bahwa para siswa yang sebelumnya kurang aktif dalam proses belajar dan mengajar menjadi lebih aktif. Hal ini dikarenakan beberapa dari sifat yang membuat tidak aktif dapat diatasi 
dalam pembelajaran ini seperti, rasa malu untuk bertanya atau berbicara di khalayak umum, merasa tidak percaya diri ataupun segan dengan teman sejawat atau guru di kelas atas kemampuan yang dimiliki tiap siswa. Sebagaimana yang ditunjukkan oleh Murbaetty bahwa Cooperative Learning dapat menumbuhkan suasana belajar yang menyenangkan ${ }^{9}$. Dengan energi positif berupa menjadi aktifnya para siswa, maka dapat memudahkan guru dalam mengembangkan proses pembelajaran dan mencapai target yang diinginkan.

Kedua, Hasil belajar dengan menggunakan metode Cooperative Learning. Pada pembahasan ini dipaparkan mengenai hasil belajar para siswa setelah digunakan metode Cooperative Learning. Data hasil belajar siswa dapat diperoleh melalui mengajukan beberapa soal yang mereka kerjakan bersama sebagaimana yang telah dipaparkan. Kemudian mengajukan angket pertanyaan yang sama kepada masingmasing siswa untuk mereka isikan secara pribadi sesuai dengan apa yang mereka rasakan setelah mengikti proses pembelajaran dengan metode Cooperative Learning.

Adapun hasil dari pertanyaan yang diajukan akan ditampilkan dalam bentuk tabel sebagai berikut:

\footnotetext{
${ }^{9}$ Murbaetty, N. S. (2017). PENGGUNAAN STRATEGI PEMBELAJARAN COOPERATIF LEARNING UNTUK MENINGKATKAN HASIL BELAJAR METODE PEKERJAAN SOSIAL JAKARTA. Jurnal Pendidikan Kewarganegaraan, Vol. 4 No. 1, 2017: 65.
} 
ALIBBAA': Jurnal Pendidikan Bahasa Arab, 2 (1), 2021

\begin{tabular}{|c|c|c|}
\hline No & ertanyaan & Data Temuan Lapangan \\
\hline 1 & $\begin{array}{l}\text { Bagaimana kesan } \\
\text { pembelajaran } \\
\text { dengan } \\
\text { pembelajaran } \\
\text { metode } \\
\text { Cooperative } \\
\text { Learning? }\end{array}$ & $\begin{array}{l}\text { - Pada pembelajaran ini, lebih dapat } \\
\text { mengedepankan kerja sama } \\
\text { - Dapat melatih mental untuk } \\
\text { berpendapat ke muka umum } \\
\text { - Lebih berani dalam mengungkapkan } \\
\text { pendapat } \\
\text { - Tidak merasa minder kepada teman } \\
\text { yang lebih pintar, karena saling } \\
\text { berbagi jawaban untuk sama-sama } \\
\text { aktif } \\
\text { - Terbantu untuk menyelesaikan tugas } \\
\text { karena setiap siswa saling membantu } \\
\text { menyelesaikan tugas }\end{array}$ \\
\hline 2 & $\begin{array}{l}\text { Apa kelebihan } \\
\text { yang didapatkan } \\
\text { dengan } \\
\text { pembelajaran } \\
\text { metode } \\
\text { Cooperative } \\
\text { Learning? }\end{array}$ & $\begin{array}{l}\text { - Tidak merasa bosan, karena lebih } \\
\text { menuntut siswa untuk lebih aktif } \\
\text { - Menumbuhkan jiwa sosial kepada } \\
\text { sesama teman } \\
\text { - Merasa termotivasi karena merasa } \\
\text { saling membuktikan kemampuan } \\
\text { terhadap kelompok lain } \\
\text { - Melatih daya pikir sesama dalam } \\
\text { memecahkan masalah atau tugas yang } \\
\text { diberikan }\end{array}$ \\
\hline
\end{tabular}




\section{Kelebihan dan Kekurangan Cooperative Learning}

Tentunya sudah menjadi fitrah alami dimana produk kehidupan pasti memiliki dua sisi yang akan ditemui yaitu hal yang menjadi kelebihan diiringi dengan hal yang menjadi kekurangan. Begitupula pada pembelajaran Cooperative Learning sebagaimana dungkapkan oleh Parker dan Jarilimek, menyebutkan kelebihan dari pembelajaran ini $^{10}$ : adanya ketergantungan positif diantara sesama siswa dalam belajar dengan seringnya berkomunikasi, lebih merespon dan mengakui setiap perbedaan yang ada diantara siswa, siswa lebih dilibatkan akan perencaan dan system pengelolaan kelas, terciptanya suasana kelas yang tidak tegang akan tekanan tugas, terciptanya jalinan hubungan yang hangat diantar sesame siswa dan juga ke pendidik, siswa lebih memiliki waktu dalam mengeksplorasi kemampuan secara perlahan didalam kelompok kecil yang telah dibagi oleh pendidik

Sedangkan menurut Dess (1991) yang menjadi kelemahan dalam pembelajaran Cooperative Learning ini adalah, ${ }^{11}$ dalam prosesnya, pembelajaran membutuhkan waktu yang cukup lama bagi siswa, sehingga terkadang tidak mencapai target kurikulum yang ditentukan, selain pada siswa, metode ini juga cukup membutuhkan waktu yang lama bagi para guru, sehingga banyak yang tidak menggunakan metode ini. Kelemahan selanjutnya yaitu membutuhkan kemampuan khusus seperti sosialiasi yang kuat bagi guru untuk terus membuat suasana diskusi berjalan santai namun tepat sasaran, serta menuntut sifat dominan siswa, yaitu sifat atau sikap untuk senang berdiskusi dan bekerja sama dalam memecahkan masalah. Nurlaila juga memperlihatkan bahwa Cooperative Learning telah meningkat kemampuan mahasiswa dalam menguasai keterampilan menulis ${ }^{12}$.

Dan juga beberapa kelebihan dan kekurangan metode Cooperative Learning dari perspektif guru dan siswa. Persepsi guru mengambarkan bahwa kelebihan yang dirasa oleh guru setelah menerapkan metode Cooperative Learning telah membuat guru lebih mudah mengkondisikan para siswa dalam bentuk kelompok. Guru

\footnotetext{
${ }^{10}$ Isjoni, Cooperative Learning, (Bandung: Alfabeta, 2009), 24.

${ }^{11}$ M. Nafiur Rofiq, "Pembelajaran Kooperatif (Cooperative Learning) dalam Pengajaran Pendidikan Agama Islam”, Jurnal Falasifa. Vol. 1 No. 1, 2010: 9.

12 Nurlaila, N., \& Muassomah, M., "The Collaboration of Herbart Method with Cooperative Learning: Optimizing writing Skills at IAIN Madura", Alsinatuna: Journal of Arabic Linguistics and Education, Vol. 5 No. 2, 2020: 147-164.
} 
menemukan konsep baru dalam metode pembelajaran sejalan dengan penerapan cooperative learing ${ }^{13}$. Dengan demikian pelajaran lebih mudah dikuasai dan mencapai target, keseimbangan dalam memahami materi yang disampaikan lebih mudah tercapai, dan nilai positif lainnya yaitu fokus peserta didik lebih kondusif dengan para siswa yang saling mengigatkan ${ }^{14}$. Hal ini digambarkan juga bahwa dengan Cooperative Learning dapat meningkatkan presentasi ketuntasan belajar siswa ${ }^{15}$.

Sedangkan yang menjadi kekurangan oleh guru setelah menerapkan metode Cooperative Learning dirasakan masih kurangnya kejujuran siswa dalam mengerjakan tugas yang diberikan, masih adanya beberapa siswa yang acuh tak acuh dalam mengerjakan tigas secara kelompok. Selain itu, terdapat kelompok yang mengandalkan beberapa orang yang dianggap mampu, terutama siswa putra yang mengandalkan siswa putri saat menulis tugas. Fenomena yang ditemukan juga terkadang dalam kelompok siswa menggunakan sisa waktu diskusi untuk bermain sehingga menimbulkan sedikit keributan, dan yang terakhir siswa saling menunjuk saat guru meminta perwakilan dari kelompok ${ }^{16}$. Hinga ditunujukkan juga dalam penelitian bahwa belum meratanya ketuntasan siswa dalam mengukuti pelajaran prakarya dan kewirausahaan ${ }^{17}$.

\footnotetext{
${ }^{13}$ Wirati, N. N., "Meningkatkan Aktivitas dan Hasil Belajar Penanganan Barang Bawaan Tamu Melalui Model Cooperatif Learning dengan Teknik Bermain Peran (Role Play)", Journal of Education Action Research, Vol. 4 No. 4, 2020: 400.

${ }^{14}$ Rochmawati, I., Sutarto, J., \& Anni, C. T., "Pengembangan Model Cooperative Learning Melalui Chained Games untuk Meningkatkan Kemampuan Kerjasama Anak Usia 5-6 Tahun", Journal of Primary Education, Vol. 6 No. 2, 2017: 147-158.

${ }^{15}$ Israil, I., "Implementasi Model Pembelajaran Cooperative Learning Tipe STAD untuk Meningkatkan Motivasi Belajar Siswa dalam Pembelajaran IPA di SMP Negeri 1 Kayangan", Jurnal Kependidikan: Jurnal Hasil Penelitian Dan Kajian Kepustakaan Di Bidang Pendidikan, Pengajaran Dan Pembelajaran, Vol. 5 No. 2, 2019: 117.

${ }^{16}$ Herianto, A., \& Ibrahim, I., "Analisis Efektivitas, Kelebihan Dan Kekurangan Desain Model Cooperative Learning Dalam Meningkatkan Motivasi Dan Hasil Belajar Geografi Lingkungan Pada Mahasiswa Program Studi Pendidikan Geografi Di Pulau Lombok", Prosiding Seminar Nasional Pendidik dan Pengembang Pendidikan Indonesia, pp. 17-27, 2018.

${ }^{17}$ Irawan, F. J., \& Ningrum, N. (2016), "Pengaruh penggunaan Model Cooperative Learning Tipe Group Investigation (GI) terhadap Hasil Belajar Prakarya Dan Kewirausahaan (PKWU) siswa Kelas X semester Genap SMK Negeri 1 Metro Tp 2015-2016”, PROMOSI: Jurnal Program Studi Pendidikan Ekonomi, Vol. 4 No. 2, 2016: 66.
} 
Perspektif siswa terkait kelebihan setelah menerapkan metode Cooperative Learning iala: siswa lebih mudah dalam melatih mental dalam menyampaikan pendapat, siswa tidak merasa terasingkan ketika tidak mampu menjawab atau aktif dalam diskusi pada umumnya, memupuk rasa peduli dan sosialisasi lebih hangat terjadi dalam kelompok diskusi, lebih aktif dalam mengungkapkan argumentasi walau belum sepenuhnya tertata dengan rapi.

Kekurangan yang terlihat oleh siswa setelah menerapkan metode Cooperative Learning ditunjukkan bahwa dalam metode ini guru lebih sedikit dalam menjelaskan materi ajar. Sejalan dengan itu, siswa lebih aktif namun agak sedikit kurang terkendali dalam memahami secara utuh materi. Demikian juga terdapat beberapa siswa/teman dalam kelompok yang kurang aktif dalam diskusi walau telah dipancing untuk aktif

\section{Kesimpulan}

Hasil penelitian ini menyimpulkan bahwa penerapan metode Cooperative Learning dalam pembelajaran membutuhkan kepiawaian guru dalam menerapkan strategi yang tepat untuk mengusai situasi dan kondusi kelas diawal hingga akhir proses belajar. Walau pembelajaran cooperative leraning ini dapat membuat siswa lebih aktif, namun tidak bisa dipungkiri seiring dengan berjalannnya waktu dan proses belajar yang dilakukan, siswa akan menemukan titik jenuh dan bosan dengan metoode belajar. Sejalan dengan itu, dibutuhkan bentuk kereatifitas yang diterapkan oleh para guru. Oleh karenanya sangat penting variasi model serta strategi pembelajaran yang terus beregenerasi di setiap pertemuan pembelajaran dengan memunculkan trik-trik baru agar siswa merasa antusias dan bersemangat dalam mengikuti proses pembelajaran. 


\section{Daftar Pustaka}

Alwan, M., "Pengaruh Strategi Pembelajaran Cooperative Learning Tipe Rotating Trio Exchange Terhadap Prestasi Belajar Matematika Siswa Mts", Jurnal Al-Muta'aliyah STAI Darul Kamal NW Kembang Kerang, 2020.

Dalimunthe, M., \& Suyanti, R. D. Pembentukan karakter dan peningkatan hasil belajar kimia siswa sma melalui pengintegrasian strategi dan media pembelajaran pada materi hidrokarbon. -, 5(02), 2016.

Erita, S., "Beberapa model, pendekatan, strategi, dan metode dalam pembelajaran matematika", Tarbawi: Jurnal Ilmu Pendidikan, Vol. 1, No. 2, 2016.

Herianto, A., \& Ibrahim, I., "Analisis Efektivitas, Kelebihan Dan Kekurangan Desain Model Cooperative Learning Dalam Meningkatkan Motivasi Dan Hasil Belajar Geografi Lingkungan Pada Mahasiswa Program Studi Pendidikan Geografi Di Pulau Lombok", Prosiding Seminar Nasional Pendidik dan Pengembang Pendidikan Indonesia, pp. 17-27, 2018.

Irawan, F. J., \& Ningrum, N. (2016), "Pengaruh penggunaan Model Cooperative Learning Tipe Group Investigation (GI) terhadap Hasil Belajar Prakarya Dan Kewirausahaan (PKWU) siswa Kelas X semester Genap SMK Negeri 1 Metro Tp 2015-2016", PROMOSI: Jurnal Program Studi Pendidikan Ekonomi, Vol. 4, No. 2, 2016.

Isjoni, Cooperative Learning, Bandung: Alfabeta, 2009.

Israil, I., "Implementasi Model Pembelajaran Cooperative Learning Tipe STAD untuk Meningkatkan Motivasi Belajar Siswa dalam Pembelajaran IPA di SMP Negeri 1 Kayangan", Jurnal Kependidikan: Jurnal Hasil Penelitian Dan Kajian Kepustakaan Di Bidang Pendidikan, Pengajaran Dan Pembelajaran, Vol. 5, No. 2, 2019.

M. Nafiur Rofiq, "Pembelajaran Kooperatif (Cooperative Learning) dalam Pengajaran Pendidikan Agama Islam", Jurnal Falasifa. Vol. 1, No. 1, 2010 
Moleong, L. J., \& Edisi, P. R. R. B., Metodologi Penelitian. Bandung: Penerbit Remaja Rosdakarya, 2004.

Murbaetty, N. S. "PENGGUNAAN STRATEGI PEMBELAJARAN COOPERATIF LEARNING UNTUK MENINGKATKAN HASIL BELAJAR METODE PEKERJAAN SOSIAL JAKARTA", Jurnal Pendidikan Kewarganegaraan, Vol. 4, No. $1,2017$.

Nurhadi, Pembelajaran Kontextual (Contextual Teaching dan Learning/CTL) dan Penerapannya dalam KBK, Malang: UIN Press, 2004.

Nurlaila, N., \& Muassomah, M., "The Collaboration of Herbart Method with Cooperative Learning: Optimizing writing Skills at IAIN Madura", Alsinatuna: Journal of Arabic Linguistics and Education, Vol. 5, No. 2, 2020.

Rochmawati, I., Sutarto, J., \& Anni, C. T., "Pengembangan Model Cooperative Learning Melalui Chained Games untuk Meningkatkan Kemampuan Kerjasama Anak Usia 5-6 Tahun", Journal of Primary Education, Vol. 6, No. 2, 2017.

Setiawan, A., Yudiana, Y., Ugelta, S., Oktriani, S., Budi, D. R., \& Listiandi, A. D., "Hasil Belajar Pendidikan Jasmani dan Olahraga Siswa Sekolah Dasar: Pengaruh Keterampilan Motorik (Tinggi) dan Model Pembelajaran (Kooperatif)". TEGAR: Journal of Teaching Physical Education in Elementary School, Vol. 3, No. 2, 2020.

Wahyuni, A., \& Abadi, A. M., "Perbandingan keefektifan pembelajaran Cooperative Learning type STAD dan type TPS pada pembelajaran bangun ruang siswa SMP". Jurnal Riset Pendidikan Matematika, Vol. 1, No. 2, 2014.

Wirati, N. N., "Meningkatkan Aktivitas dan Hasil Belajar Penanganan Barang Bawaan Tamu Melalui Model Cooperatif Learning dengan Teknik Bermain Peran (Role Play)", Journal of Education Action Research, Vol. 4, No. 4, 2020. 
ALIBBAA': Jurnal Pendidikan Bahasa Arab, 2 (1), 2021

Zaman, B, "Implementation of Cooperative Learning Strategies in Islamic Religious Education". IJECA (International Journal of Education and Curriculum Application), Vol. 3, No. 2, 2020. 